\title{
Test Studies on the Corrosion Features for the Bridge Foundations Durability in a Household Refuse Landfill Environment
}

\author{
Fangyuan Li*, Junchao Huang and Yin Shen
}

Department of Bridge Engineering, School of Civil Engineering, Tongji University. 1239 Siping Road, Shanghai 200092, P.R. China

\begin{abstract}
Generally, the bridges or buildings cannot be constructed on a refuse landfill, since the special chemical compositions and microorganisms in landfill will impose adverse effects on the concrete foundations. Especially, the impacts on their durability are still unknown. The purpose of this paper is to get the corrosive features of a refuse landfill to give suggestions for the durability design of the structure's foundation. The present work is based on a bridge construction in Linhai Road, Shanghai, which should pass through a household dump landfill in a rare environment, by means of a low-bridge crossing. With the aims of ensuring the durability in long-term service and providing some reference experiences, we have performed sampling tests on the bridge pile foundations under this corrosive environment, in terms of chlorine ion content, electric flux and strength. With regard to the positions along the radial direction of pile sections, the chloride ion concentrations varies slightly and negligibly with the varying coring depths and increases with the varying coring depths, indicating that the permeability in pile foundations is enhanced gradually with the increasing buried depths. Considering the calculated permeability coefficients, the concretes with the adopted compositions doesn't meet the expected values. The measured electric flux of concretes under sewage condition is obviously higher than it is under standard curing condition, suggesting that the hazardous substances significantly affects the anti-permeability performance of concretes under on-site geological conditions. The damages of dump environment on the concrete durability of the bridge pile foundations were accessed.
\end{abstract}

Keywords: Bridge pile foundation, concrete durability, household garbage dump, chloride ion content, electric flux, coring test.

\section{INTRODUCTION}

Nowadays, reinforced concrete (RC) still plays a predominant role in the field of bridge construction all over the world. With technological advancements, both concrete and reinforcing steel bar materials have made great progresses. However, the durability problem of concrete bridges, which often occurs during the long-term applications, has attracted increasing attention by designers. This issue is particularly serious for the bridges in coastal, arctic-alpine and other special geological regions [1]. Currently, most of engineering accidents are directly or indirectly induced by the decline in concrete's durability, which has aroused great attention by many engineers and designers world over. Since the end of the last century, studies regarding the durability of various engineering materials have become increasingly intensive; especially, studies on concrete and reinforcing bar materials. After entering the new century, people have obtained considerable achievements in the studies of material's durability, mainly focusing on carbonation, acid and alkali corrosions of concretes, rut corrosions of reinforcements, freezing-thawing effects and so on [2, 3]. The durability studies have also conducted under special

\footnotetext{
*Address correspondence to this author at the Project (No.2013CB036303) supported by the National Basic Research Program of China (973 Program); Tel: +86-21-65983096; E-mail: fyli@ tongii.edu.cn
}

environments, including alpine frozen-soil regions, oceans, wetlands, saline-alkali soils and etc [3-7].

In addition to the general corrosion features, the landfill exhibits some special features to its surrounding buildings [8-10], mainly including: diversity of corrosion forms, complexity of corrosion mechanisms and imperceptibility of corrosion location. In terms of environmental media, the corrosions in landfill can be classified into gas corrosions, liquid corrosions, and the multiple corrosions induced by interactions of gases, liquids and organisms. With respect to the corrosion mechanisms of refuses and their by-products on buildings, no specialized studies have been performed until now. In accordance with the current research results, we can foresee the complexity of mechanisms, including complicated physiochemical corrosions and biochemical corrosions. The bridge foundations in the example engineer works are buried in refuses, so the observations are inconvenient. Besides, the distance between the bottom of bridge and the dump surface is only $0.5 \mathrm{~m}$. To sum up, the bridge foundation is hidden in disgusting and hazardous surroundings, making it difficult to be inspected and monitored chronically and technically except in special circumstances.

So far, studies concerning the durability of buildings on refuse landfills are still scant, mainly on account of several restrictions on the constructions on or around the landfills in 
various countries [11]. For instance, in China, according to the related regulations for the site-selection of refuse landfills in Standard for Pollution Control on the Landfill Site of Municipal Solid Waste (GB16889-2008), household refuse landfill should be located far away from some sensitive objects, such as local residences, surface waters, expressways, trunk roads for transportation, railways, airports, military bases, and etc. Additionally, planning controls are required in line with the assessments on environmental impacts.

With reference to bibliographic retrieval results, the current studies on refuse landfills are primarily confined to the following aspects: pollution characteristics, environmental protections, disposal and recycle of refuses, geological conditions, and etc [8, 10, 12]. However, there are nearly no related reports to date on the studies regarding the refuses' corrosion behaviors and the constructions' durability. In China, with the rapid expansions of cities and intensive protection of soils, the existing refuse landfills are likely to be reused or recycled when encountering several situations, listed as follows.

The original dump conforms to the related regulations, and moreover, both the location and backfilling materials meet the environmental requirements. On an environmental-protection premise, the dump can be reconstructed for a special building or reused in a new project.

(ii) The refuse landfill was built in a particular geographical location originally. Now, this location should be recycled for some purposes, such as the construction for traffic or environmental treatment facilities.

(iii) The original landfill is small, which can be recycled through relocation or earth replacement.

(iv) Without a legitimate examination and approval, the existing refuse landfill cannot meet the requirements in the related regulations. However, the landfill is found in the exploration. According to the completed design, we still need to construct the structures passing through this landfill.

Generally, the corrosion phenomena in dumps are directly related to two factors: one is the intrinsic characteristics of dump leachates and the other is the characteristics of gases and volatile substances produced by degradation of organic matters in refuses and leachates. This paper just focused on the liquid corrosives.

Dump leachate is one type of mixed organic pollution with high concentration, complex composition and considerable corrosivity. The COD content is as high as $60000 \sim 80000 \mathrm{mg} / \mathrm{L}$, while the total residue can be up to $2350 \sim 35700 \mathrm{mg} / \mathrm{L}$. The compositions of leachate, directly affected by the components of refuse, are fairly complicated. As reported, there are at least dozens of inorganic matters and heavy metals, and hundreds of organic matters including various pathogenic microorganisms, carcinogens and cancerpromoters contained in leachate. Similarly, the $\mathrm{pH}$ value of leachate depends on the refuse's fermentation degree. At the early stage, the generated leachate is of weak acidity, with a $\mathrm{pH}$ value below 6.5. With time, the $\mathrm{pH}$ value increases gradually to be over 8.0 and remains constant, i.e., the subsequent leachate is alkaline. The studies indicate that the leachate imposes slight corrosive effects on the building materials such as concretes; and moreover, owing to the fact that a large number of suspended substances in leachate are prone to forming scaling, the leachate can be objectively protective to the concrete surfaces where scaling occurs.

The corrosion mechanism of refuse leachate and the related gases on concretes are extremely complex, covering many fields such as physics, chemistry, materials, microorganisms, and etc. Studies on the quantitative analysis are still absent to date; however, the qualitative studies indicate that the corrosions are primarily induced by cement hydrates, followed by the aggregates (for example, the aggregate containing a certain volume of limestone). Besides, corrosions induced by dissolution and expansion exist simultaneously.

In the present work, based on a practical engineering work, we have performed an in-depth study on the corrosion features of a refuse landfill, and the corresponding concrete durability of bridge pile foundations under this special corrosion environment.

\section{CORROSION FEATURES OF THE REFUSE LANDFILL}

As shown in Fig. (1), the planed Linhai Road, with a width of $50 \mathrm{~m}$, is denoted as the red lines. The green lines are $20 \mathrm{~m}$ away from two sides of the red line. Starting from the point A20, the road ends at the point A30, running across Minhang District, Nanhui District and Fengxian District. The stake marks of the road from the starting point to the terminal point are from $\mathrm{K} 1+230$ to $\mathrm{K} 27+300$. The road, with an overall length of $26.070 \mathrm{~km}$, is designed in accordance with the first-class highway standards, on which the rated velocity is $80 \mathrm{~km} / \mathrm{h}$. When entering into the construction site, the construction unit found a refuse landfill in the subgrade, located at Huinan Village, Pujiang Town, Minhang District (the stake marks in the mileage ranges from $\mathrm{K} 15+340$ to $\mathrm{K} 15+640$ ). The dump was formed approximately 4 years ago, with the size of $120,000 \mathrm{~m}^{2}$. It can be observed from Fig. (1) that the subgrades in this range pass through the dump. By consulting the village committee, we are informed that the dump used to be vegetable fields, parts of which were ponds. Accordingly, this area, abounding in water and sludge, was then excavated to be a landfill.

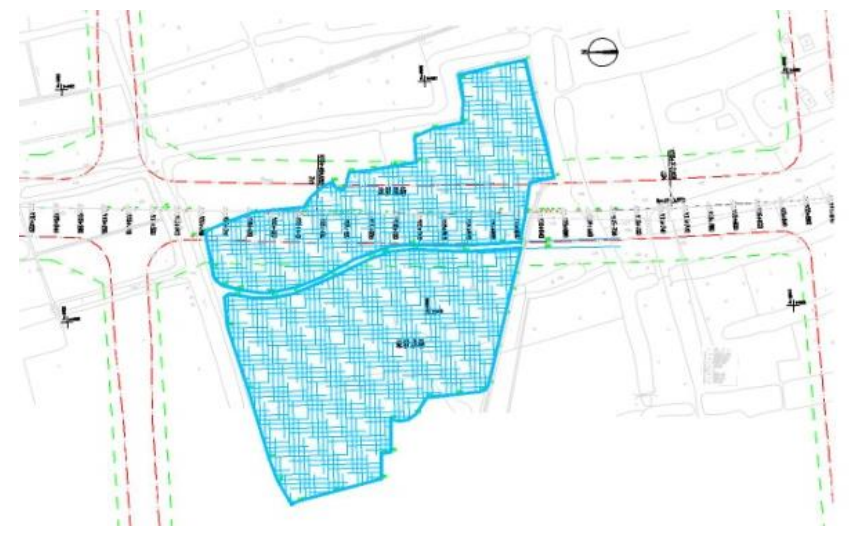

Fig. (1). Planar graph of the refuse landfill. 
As a simple landfill, the dump is approximately $2.5 \sim 7.0$ $\mathrm{m}$ deep, with comparatively loose structure and poor compactness. The surfaces of some areas are covered with a layer of laminated soils, preventing the exposure of refuse. The leachates are discharged disorderly, without any rain and sewage diversion facilities. The sewage deposits at the lowlying areas and no guided disposal measures are taken. Additionally, there are no workers and no supervision of the landfill, as evident in Fig. (2).

As displayed in Fig. (2), the landfill is surrounded by harsh environments, lacking some necessary protection measures. Besides, the dump is illegal, without any seepage proofing and pollution control measures. Since the refuses are thrown away randomly, the foundation soils are distributed unevenly. More seriously, the intensity of foundation is reduced drastically, also characterized by uneven distributions.

To identify the properties of soils in the landfill, we have excavated several soil samples around the landfill and collected them for analysis. Fig. (3) displays the sample holes at either side of the bridge, with the diameters of top and bottom openings of 4 and $1.5 \mathrm{~m}$, respectively. From Fig. (4), we can easily observe that the sludge at the bottom of holes are black clays soaked in sewage, and therefore the texture is quite soft. The actual depth of sludge is approximately $1.0 \mathrm{~m}$.

The holes were dug until the undisturbed soil appeared. The measured depths of holes and sewage is listed in Table 1.

As concluded from field observation and sampling tests, the buried depth of the dump is approximately $4.77 \mathrm{~m}$. In foundation soils, the undesirable corrosive media are distributed unevenly. During the construction of pile foundations, the corrosive media in refuse layer and the lower sandy soil layer are diffused with ground water, making the corrosion conditions vary at different locations and depth. Accordingly, aiming at conducting the anticorrosion design and treatments of bridge foundation and reducing the related adverse impacts, we should make indepth analysis on the environmental components around the
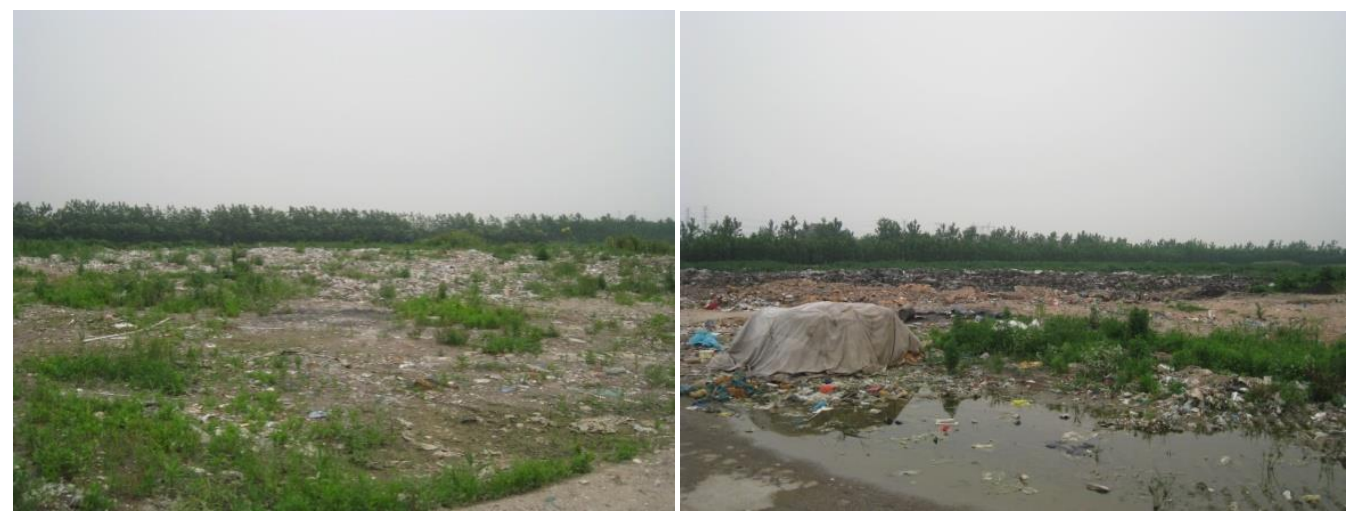

Fig. (2). Pictures of the refuse landfill.

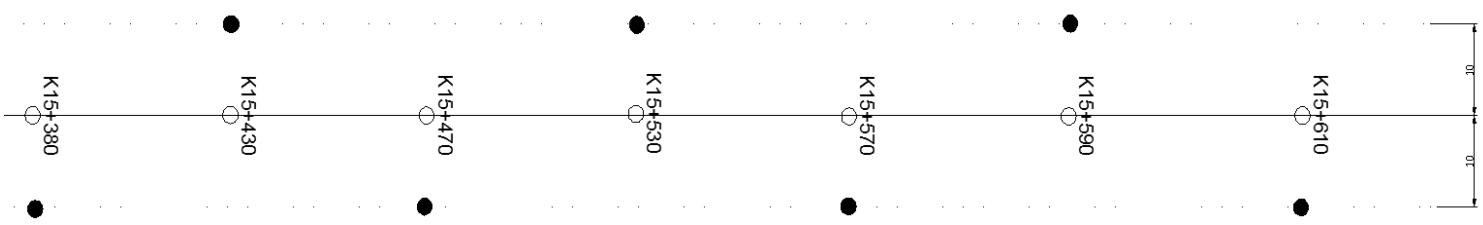

Fig. (3). Schematic diagram of the distribution of sample holes.

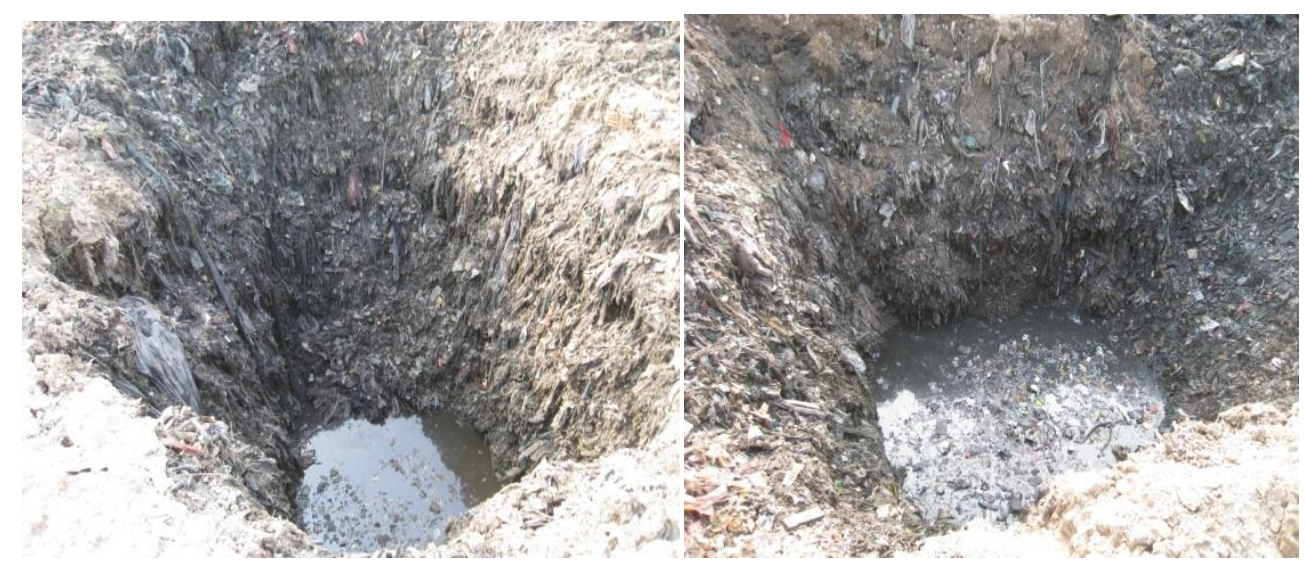

Fig. (4). Pictures of sample holes. 
bridge, and obtain accurate information of the corrosion environment.

\section{TESTS ON THE CORROSION ENVIRONMENT AND RESULTS}

The monitoring on $\mathrm{pH}$ value and COD of water seepages in the landfill were conducted by Shanghai Environmental Health Monitoring Center, the results are listed in Table 2. We can observe that the water in the landfill is slightly alkaline and polluted mainly by the refuse leachates.

According to Tentative Standards of Industrial Wastewater Discharge in China, the maximum allowable concentration of industrial wastewater should be less than $100 \mathrm{mg} / \mathrm{l}$, while the wastewater from papermaking, tanning, and absorbent cotton factories should be below $500 \mathrm{mg} / \mathrm{l}$. With reference to water quality standards in Japan, the maximum allowable concentration of COD should be less than $120 \mathrm{mg} / \mathrm{l}$ per day.

Water samples have also been taken to Shanghai Municipal Engineering Design Institute (the engineering exploration organization) for analysis, with the main conclusions of the water-quality report are listed as follows.

(i) In s type-III environment, the groundwater in the landfill exhibits slight corrosion to concrete;

(ii) After a long-term soaking, the groundwater in the landfill exhibits week corrosion to steel bar;

(iii) After several alternations of drying and wetting, the groundwater in the landfill exhibits strong corrosion to steel bar;

(iv) The groundwater in the landfill exhibits moderate corrosion to steel structure.

In other words, the pile foundations soaked in the groundwater (or leachate) suffer from slight corrosions; while the piles components above the groundwater (or leachate) sustain severe corrosions.

\section{TESTS ON THE CONCRETE DURABILITY OF PILE FOUNDATIONS}

Focusing on the above-described corrosive environment, we have studied several anti-corrosion protective measures for concretes, with the purpose of ensuring the durability of bridge foundations and prolonging their service life. In the present study, we first, explored the durability design for concrete, and then studied the on-site concrete maintenance in a landfill environment, combined with the corresponding sampling tests. Finally, in accordance with the relevant specifications, the environmental conditions of the landfill and the appropriate durability design requirements were identified.

\subsection{Concrete Material Design}

In consideration of the particularity of foundation conditions (since no similar environmental conditions have been encountered in the previous engineering construction), we should perform several relevant tests to discuss the effects of ground environment on the durability of pile foundations.

According to the chlorine ion content, as investigated in the groundwater quality report, in combination with the gradation and strength of the concretes in precast piles [2,5], the technical requirements of concretes were drawn up as follows: The strength grade is C35; the slump degree of insitu casting is approximately $(200 \pm 20) \mathrm{mm}$; the permeable electric quantity $(\mathrm{Q})$, as required in chloride ion permeation resistance, is below $1300 \mathrm{C}(\mathrm{Q} \leq 1300 \mathrm{C})$ and the chloride ion diffusion coefficient is below $3.0\left(10-12 \mathrm{~m}^{2} \cdot \mathrm{s}-1\right)$.

With the extra coefficient of concrete strength taken into account, the strength in tests was set to be about 140 150

Table 1. Measured data.

\begin{tabular}{|c|c|c|c|c|}
\hline Serial Number & Stake Marks & Measured Elevation/m & The Depth of Holes/m & The Depth of Sewages/m \\
\hline \hline 1 & K15+380 & 4.966 & 4.2 & 1.2 \\
\hline 2 & K15+430 & 5.366 & 4.6 & 1.4 \\
\hline 3 & K15+470 & 5.033 & 3.6 & 1.1 \\
\hline 4 & K15+530 & 6.313 & 7.0 & 5.2 \\
\hline 5 & K15+570 & 6.495 & 4.3 & 3.6 \\
\hline 6 & K15+590 & 6.362 & 4.8 & 1.8 \\
\hline 7 & K15+610 & 6.274 & 4.6 & 4.0 \\
\hline
\end{tabular}

Table 2. Monitoring results of water seepages in the landfill.

\begin{tabular}{|c|c|c|}
\hline Number of Samples & PH & COD $_{\text {cr }}(\mathbf{m g} / \mathbf{L})$ \\
\hline \hline $2 \#$ & 8.0 & 602 \\
\hline $6 \#$ & 7.7 & 626 \\
\hline $7 \#$ & 8.5 & 1860 \\
\hline
\end{tabular}


percent of the designed strength, identified as $52.5 \mathrm{MPa}$. Conclusively, the optimal composition of concrete is presented as follows: cement $\left(212 \mathrm{~kg} / \mathrm{m}^{3}\right)$, fly ash (142 $\left.\mathrm{kg} / \mathrm{m}^{3}\right)$, Point-AC strengthening agent $\left(71 \mathrm{~kg} / \mathrm{m}^{3}\right)$, sand $(707$ $\left.\mathrm{kg} / \mathrm{m}^{3}\right)$ and stone $\left(1017 \mathrm{~kg} / \mathrm{m}^{3}\right)$. The measured results of the designed concrete includes: water-binder ratio is 0.36 ; the slump degree is $225 \mathrm{~mm}$; the permeable electric quantity is $368 \mathrm{C}$ and the chloride ion diffusion coefficient is 2.81 (10$\left.12 \mathrm{~m}^{2} \cdot \mathrm{s}^{-1}\right)$.

Generally, there are three indexes to define the concrete durability; specifically, strength, chloride ion diffusion coefficient, and electric flux [13, 14]. In the present study, we have examined the concrete performance based on these three measured indexes, which will be elaborated in the following sections.

To make the data more accurate and comparable, we have performed the maintenance under two conditions: standard curing and in-situ sewage, with a same period of 28 days. In the tests, the concrete corrosions at different depths of pile foundation were studied and compared. Test piles were casted on the spot, with the adoption of $\mathrm{C} 30$ concrete.

\subsection{Tests Results of the Durability Parameters}

\subsubsection{Chloride Ion Permeability}

Based on Specification for Deterioration Prevention of Highway Concrete Structure, the measurements of chloride ion diffusion coefficient should be conducted by selecting the cylindrical samples with the diameter and length of 100 and $50 \pm 2 \mathrm{~mm}$, respectively.

There are two objectives for the tests: one is to investigate if any sewage flowed into the concrete during pile-forming, i.e., if any sewage mixed in the formed pile; the other is to explore the diffusions of chemical components in the sewage into the pile concretes and their effects. Accordingly, the samples should be taken according to the following requirements.

(i) The coring barrel should be placed below the normal depth of sewage in the landfill, i.e., the sampled concretes should be soaked completely in the sewage. (ii) Aiming at obtaining some representative data, the coring should be conducted along two directions, the axial direction of piles and the radial direction of barrel section.

(iii) As shown in Fig. (5a), along the axial direction, three samples should be taken from the barrel center to the periphery, with a same interval of $260 \mathrm{~mm}$. The depth of coring should be at least $400 \mathrm{~mm}$ below the lowest sewage level. At least six cylinders with a length of 50 $\mathrm{mm}$ were obtained, in which three cylinders were used for the present tests and the rest were used for the tests for electric flux. Under poor conditions, only two samples were taken, located at the innermost and outermost positions along the axial direction.

(iv) As shown in Fig. (5b), along the radial direction, three samples were taken below the lowest sewage level, with a same length as the section radius of barrel. Similarly, under poor conditions, only three samples at the same depths were taken.

During the tests, for convenient data sorting, we have labeled the samples at different coring depths with different serial numbers; namely, No. 1 denotes the central parts of piles, No. 2 denotes the central parts of the coring barrel radius, and No. 3 denotes the outermost parts along the axial direction. The coring samples, parts of which are displayed in Fig. (6), present different chloride ion permeability on account of their different depths. The chloride ion concentrations of different samples were measured, as shown in Table 3. For each sample, the concentrations were measured at different depths. The measured chloride ion concentrations under different maintenance conditions are compared and listed in Table $\mathbf{4}$, with the corresponding variation rules presented in Fig. (7).

From the data in Table $\mathbf{3}$ and Table $\mathbf{4}$ and the variation rules in Fig. (7), some main conclusions can be obtained, as listed below.

(i) With regard to the positions along the radial direction of pile sections, the chloride ion concentrations of the No. 1 sample (the samples located at the center of coring barrel) varies slightly and negligibly with the

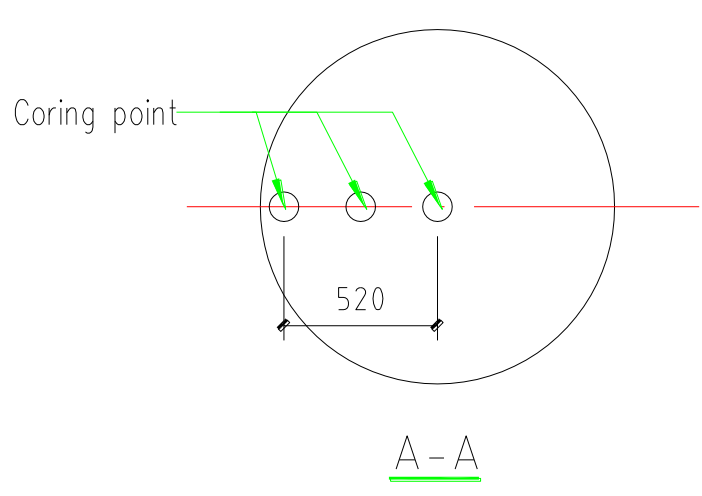

(a) Coring positions along the radial direction

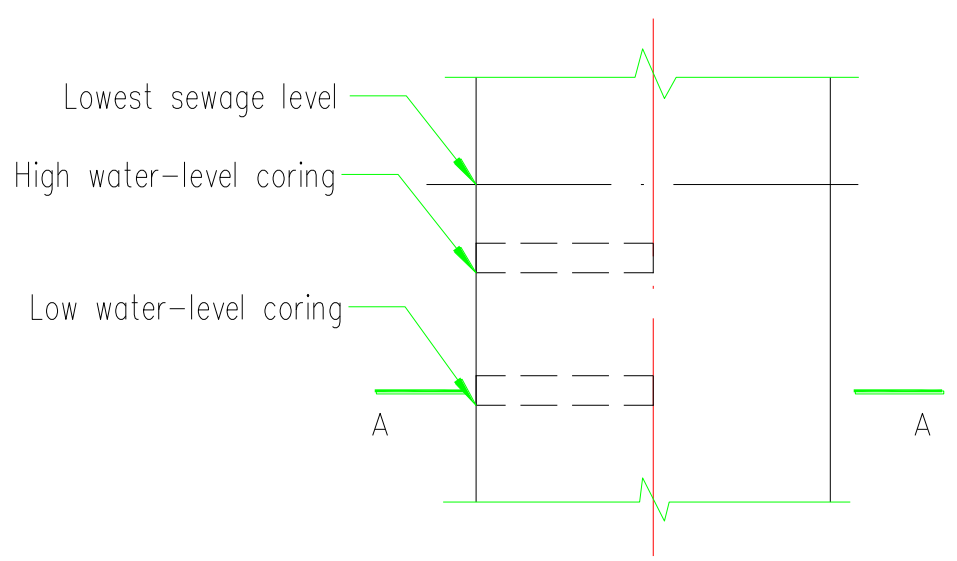

(b) Coring positions along the height direction

Fig. (5). Schematic diagram for the coring location. 


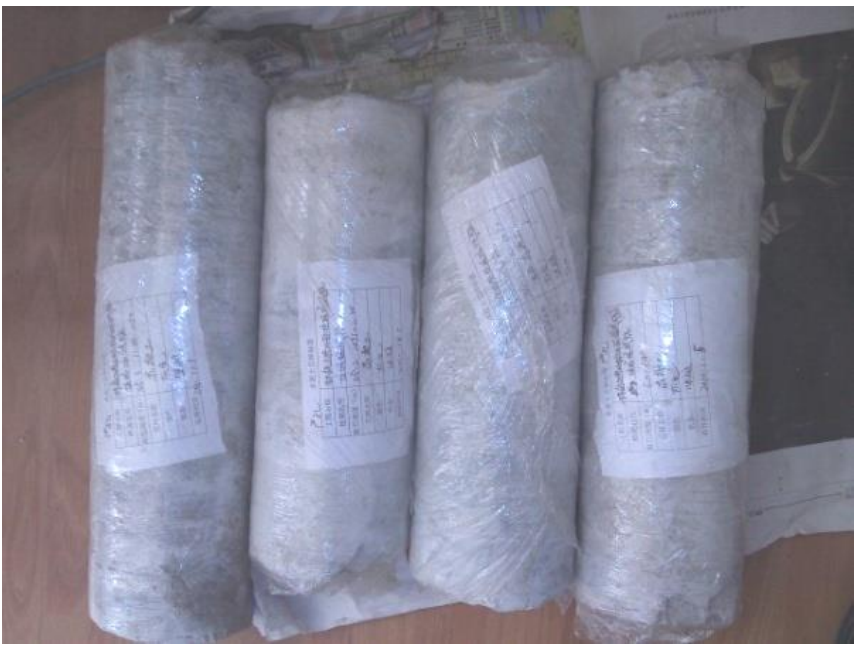

Fig. (6). Coring samples used in tests.

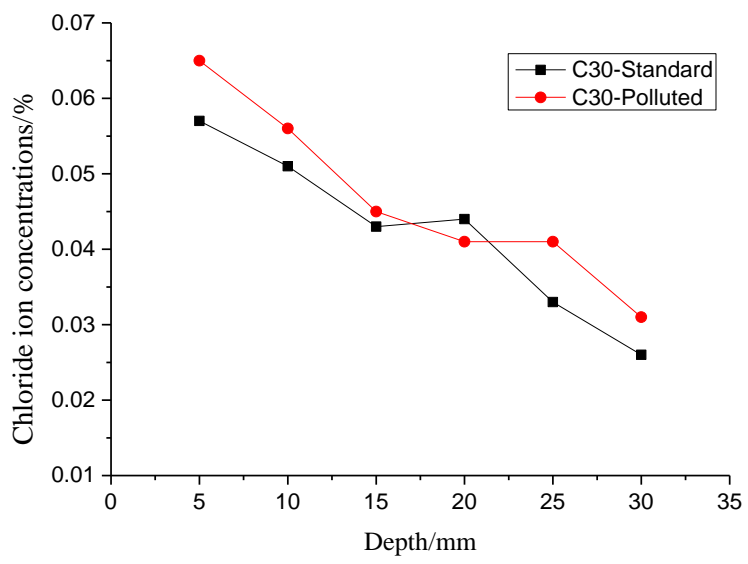

Fig. (7). Variation rules of chloride ion concentrations with the varying depths.

Table 3. Chloride ion concentrations for different samples at different coring depths (Unit: \%).

\begin{tabular}{|c|c|c|c|c|c|c|}
\hline Jumber & $1 \# 5.12-5.4 \mathrm{~m}$ & 1\# 11.2-11.5m & $2 \# 5.13-5.4 \mathrm{~m}$ & 2\# 11.8-12.1m & 3\# 5.3-5.7m & 3\# 11.3-11.6m \\
\hline $5 \mathrm{~mm}$ & 0.0467 & 0.0468 & 0.0504 & 0.0502 & 0.0516 & 0.0542 \\
\hline $10 \mathrm{~mm}$ & 0.0472 & 0.0474 & 0.0478 & 0.0507 & 0.0522 & 0.0534 \\
\hline $15 \mathrm{~mm}$ & 0.0458 & 0.0466 & 0.0473 & 0.0486 & 0.0507 & 0.0544 \\
\hline $20 \mathrm{~mm}$ & 0.0463 & 0.0471 & 0.0474 & 0.0495 & 0.0508 & 0.0527 \\
\hline $25 \mathrm{~mm}$ & - & - & - & - & - & 0.0515 \\
\hline $30 \mathrm{~mm}$ & - & - & - & - & - & 0.0511 \\
\hline
\end{tabular}

Note: H-Height direction along the pile length, R-Radial direction.

varying coring depths.

(ii) The chloride ion concentrations of the No.2 and No.3 samples increases by approximately $0.002 \% \sim 0.008 \%$ with the varying coring depths, indicating that the chloride ion permeability in pile foundations is enhanced gradually with the increasing buried depths.

(iii) In a pile section, the chloride ion concentration reduces steadily from the periphery to the center. Though chloride ions can permeate into the concrete components, their effects decrease as the depth of section increases, which can be neglected beyond a certain range.

(iv) Compared with the curing samples under standard maintenance conditions, the samples under sewage conditions present an approximate $0.002 \% \sim 0.008 \%$ increase in chloride ion concentration, which implies 
that the sewage in dumps can indeed impose a certain effects on concretes, with a slow permeability rate. By translation, the permeability coefficients under different maintenance conditions, C30-standard and C30polluted, are 6.02 and $8.1\left(10^{-8} \mathrm{~m}^{2} \cdot \mathrm{S}^{-1}\right)$, respectively. Based on the calculated permeability coefficients, the concrete with the adopted compositions doesn't meet the expected values.

\subsubsection{Chloride Ion Electric Flux}

Based on Specification for Deterioration Prevention of Highway Concrete Structure, the measurements of chloride ion electric flux should be conducted using the cubic samples with the size of $100 \times 100 \times 100 \mathrm{~cm}$, or the cylindrical samples with the radius and length of 100 and $50 \mathrm{~mm}$, respectively. Since the coring samples are cylinders, the cylindrical samples were selected in the present study. As stated previously, the tests were conducted on the samples taken along two directions. Considering the coring workload, we have adopted the redundant parts of the exiting coring barrel in the present measurements; i.e., when taking samples for the measurements of permeability coefficients, the coring depth increases correspondingly.

Along the radial direction, the coring depth equals to the pile radius, which is approximately $200 \mathrm{~mm}$. Except for the permeability coefficients tests, the remaining samples were used for the measurements of electric flux. As reported, the electric flux of $\mathrm{C} 30-\mathrm{C} 45$ concretes should be less than $1300 \sim 1500 \mathrm{C}[15,16]$. The measured results of chloride ion electric flux at varying depths under two maintenance conditions are listed in Table $\mathbf{5}$ and Table $\mathbf{6}$.

As can be concluded from Table 5 and Table 6, the measured values of electric flux under two maintenance conditions exceed the expected values, which implied that the proportion of concrete should be readjusted by experiments. The measured electric flux of concretes under sewage condition is obviously higher than it is under standard curing condition, suggesting that the hazardous substances significantly affects the anti-permeability performance of concretes under on-site geological conditions.

In concrete durability design, the controlling of chlorine ion content is of most significance. According to the relevant specifications and the comparisons of experimental data [15, $17,18]$, the concrete strength should exceed C35 grade while the chlorine ion content should be below $0.1 \%$, when placed in the most severe corrosion environment. It can be concluded from the experimental data that the maximum chlorine ion content of concrete maintained in sewage curing is at approximately $0.06 \%$, which is below the requirements in specifications. Unfortunately, the measured electric flux of concretes maintained in sewage curing far exceeds the expected value. During the long-term utilization, the chlorine ion content of concretes may probably exceed the safety standard, in that the anti-permeability cannot meet the requirements.

In actual constructions and applications, the following suggestions are proposed for the improvement of concrete durability, based on the results in the present study.

(i) In terms of concrete proportion, the dosage of cement is $212 \mathrm{~kg} / \mathrm{m}^{3}$, which is less than the minimum cement dosage in the highest standard for durability. Consequently, the concrete proportion can be revised.

(ii) Some additives can be added to improve the antipermeability performance of concretes, such as industrial residues. On the other side, the additives contain a certain amount of chloride ions, so the doping content of additives should also be limited.

(iii) In practical projects, we can increase the thickness of concrete covers of bridges, to offer further protection

Table 4. Measured chloride ion concentrations under different maintenance conditions (Unit: \%).

\begin{tabular}{|c|c|c|c|c|c|c|}
\hline Depth & $5 \mathrm{~mm}$ & $10 \mathrm{~mm}$ & $15 \mathrm{~mm}$ & $20 \mathrm{~mm}$ & $25 \mathrm{~mm}$ & $30 \mathrm{~mm}$ \\
\hline \hline C30-Polluted & 0.065 & 0.056 & 0.045 & 0.041 & 0.041 & 0.031 \\
\hline C30-Standard & 0.057 & 0.051 & 0.043 & 0.044 & 0.033 \\
\hline
\end{tabular}

Notes: C30-standard denotes the concretes after curing for 28 days under standard curing conditions, while C3-polluted denotes the concretes after curing for 28 days under sewage conditions.

Table 5. Measured electric flux of concretes at varying coring depths.

\begin{tabular}{|c|c|c|c|c|c|c|}
\hline $\begin{array}{l}\text { Number } \\
\text { Height/m }\end{array}$ & $\begin{array}{c}1 \# \\
5.1-5.4\end{array}$ & $\begin{array}{c}1 \# \\
11.2-11.5\end{array}$ & $\begin{array}{c}2 \# \\
5.13-5.4\end{array}$ & $\begin{array}{c}2 \# \\
11.8-12.1\end{array}$ & $\begin{array}{c}3 \# \\
5.3-5.7\end{array}$ & $\begin{array}{c}3 \# \\
11.3-11.6\end{array}$ \\
\hline
\end{tabular}

Table 6. Measured electric flux of concretes under different maintenance conditions.

\begin{tabular}{|c|c|c|}
\hline Number & C30-Polluted & C30-standard \\
\hline \hline Electric flux /C & 2224 & 1756 \\
\hline
\end{tabular}


Table 7. Measured concrete strength using core-drilling method (Unit: MPa).

\begin{tabular}{|c|c|c|c|c|c|c|}
\hline Number & 1\# & 1\# & 2\# & 2\# & 3\# & 3\# \\
\hline \hline Depth/m & $10.4-10.7$ & $10.9-11.2$ & $10.0-10.5$ & $11.1-11.5$ & $9.9-10.3$ & $10.3-10.6$ \\
\hline A & 52.48 & 57.35 & 50.05 & 52.25 & 53.06 & 48.76 \\
\hline B & 54.78 & 53.67 & 54.89 & 53.16 & 51.16 & 52.12 \\
\hline Average & 53.63 & 55.51 & 52.47 & 52.71 & 52.11 & 50.44 \\
\hline
\end{tabular}

for steel bars.

\subsubsection{Concrete Strength}

According to the test requirements for concrete strength, 6 cubic concrete samples with the same size of $100 \times 100 \times$ $100 \mathrm{~mm}$, were selected as the testing piles and maintained in standard environment. The cubes were employed for the measurements of concrete strength and elastic modulus. Additionally, 12 cubic concrete samples with the same size of $100 \times 100 \times 100 \mathrm{~mm}$, casted on site, were placed in the sewage of dumps for maintenance. The samples were then performed in the tests for different ages.

Two kinds of samples should be maintained for the same periods in order to acquire more comparative data. The samples were labeled as different marks to distinguish from two curing environments. The measured results of concrete strength are listed in Table 7.

The measured values of concrete strength are fairly high, and the 28-day concrete strength exceeds the C30 strength provided by the construction organization. The results indicate that the concrete strength varies little under the corrosion environments. Theoretically, due to the effects by the microorganisms on the surface, the concrete strength will be changed to a certain degree. However, the effects of microorganisms are minor since the curing period is limited.

The results indicate that the durability of concrete components suffers from significant impacts under this special condition. Accordingly, the concrete should be given more attention for protection treatments, comparing with the concrete under normal conditions, so their reliability can be ensured in long-term service.

According to the experimental results, for a better control of chlorine ion concentration in concretes and improving their anti-permeability performance, the design for pile foundations of bridges constructed on a refuse landfill should pay more attention to the following points: the improvement of concrete grade by varying the proportion, the suitable addition of additives, the increase of thickness of covering layer, the adoption of protective coatings and backfilling for changing the geological conditions.

\section{CONCLUSION}

When building bridges on a refuse landfill, i.e., under a special geological condition, the concrete durability will be different from the normal conditions, since the foundations of bridge are directly buried in the dump's soil. In the present work, we have performed the tests to measure the two key indexes regarding the concrete durability, specifically, the chloride ion concentration and electric flux of concrete.

As can be concluded from the results of geological survey and water-quality tests, the soils in the dump are weakly alkaline. More seriously, in a drying-wetting alternation environment, the soils exhibit strong corrosions to reinforced concrete constructions.

The experimental results indicate that, after curing for 28 days, the chloride ion concentration of concretes satisfies the requirements in the specification, which is below the maximum standard. However, the corresponding electric flux exceeds the standard level.

In conclusion, after long-term applications, the chloride ion concentration of pile foundations buried in dump's soil, are likely to be above the standard requirements, which may impose adverse effects on the bridge.

It can be concluded from the experimental data that the results exhibit certain differences from the expected values, suggesting that several uncontrollable factors exist in the dump's environment. Moreover, some independent experiments should be performed based on the designed concrete's proportion, so that more reasonable proportion can be identified.

\section{CONFLICT OF INTEREST}

The authors confirm that this article content has no conflict of interest.

\section{ACKNOWLEDGEMENTS}

None declared.

\section{REFERENCES}

[1] C. Andrade, A. Bettencourt-Ribeiro, N. R. Buenfeld, Concrete durability - an approach towards performance testing, Meterial \& Structure, vol. 32. France, pp. 163-173, 1999.

[2] S. B. Bhide and P. C. Taylor, "Specifying high performance concrete for durable bridges," Indian Concrete Journal, vol. 79, pp. 49-54, 2005.

[3] G. Li, F. Hu and Y. Wu, "Chloride ion penetration in stressed concrete," Journal of Materials in Civil Engineering, vol. 23, pp. 1145-1153, 2011.

[4] M. Ghrici, S. Kenai and M. Said-Mansour, "Mechanical properties and durability of mortar and concrete containing natural pozzolana and limestone blended cements," Cement and Concrete Composites, vol. 29, pp. 542-549, 2007.

[5] S. R. Hillier, C. M. Sangha, B. A. Plunkett, and P. J. Walden, "Effect of concrete curing on chloride ion ingress," Magazine of Concrete Research, vol. 52, pp. 321-327, 2000. 
[6] M. Najimi, M. Jamshidi and A. Pourkhorshidi, "Durability of concretes containing natural pozzolan," Proceedings of Institution of Civil Engineers: Construction Materials, vol. 161, pp. 113-118, 2008.

[7] M. Najimi and A. R. Pourkhorshidi, "Properties of concrete containing copper slag waste," Magazine of Concrete Research, vol. 63, pp. 605-615, 2011.

[8] J. He, "Industrial wastes and living garbage multiple combinations of concrete strength test," Journal of Henan Normal University. Natural Science, vol. 40, pp. 104-107, 2012.

[9] X. Y. Zhang, "Study on the Landfill Technology of the Rural Living Garbage Ecological Sanitary," in Advances in Intelligent Systems Research. H. S. Wang, Ed. Paris: Atlantis Press, 2013, vol. 64, pp. 156-160.

[10] X. Wu, "Present situation of municipal living garbage disposal and option of disposal technics in Sichuan Province, China," Journal of Chengdu University of Technology (Science \& Technonogy Edition), vol. 31, pp. 558-561, 2004.

[11] M. Shekarchi, F. Moradi-Marani and F. Pargar, "Corrosion damage of a reinforced concrete jetty structure in the Persian Gulf: A case study," Structure and Infrastructure Engineering, vol. 7, pp. 701713, 2011.

[12] Q. Zhao, L. Bu, J. Yang, and K. Wang, "Spectroscopy properties of dissolved organic matter in landfill leachate during corrosion cell- fenton post-treatment," Chinese Journal of Environmental Science, vol. 32, pp. 2378-2384, 2011.

[13] M. S. Islam and T. Kishi, "Proposal of analysis methods based on stagnation of chloride ion in concrete," Journal of Advanced Concrete Technology, vol. 11, pp. 374-382, 2013.

[14] M. Uysal, K. Yilmaz and M. Ipek, "The effect of mineral admixtures on mechanical properties, chloride ion permeability and impermeability of self-compacting concrete," Construction and Building Materials, vol. 27, pp. 263-270, 2012.

[15] Delagrave, M. Pigeon, J. Marchand, and E. Revertegat, "Influence of chloride ions and $\mathrm{pH}$ level on the durability of high performance cement pastes (part II)," Cement and Concrete Research, vol. 26, pp. 749-760, 1996.

[16] Y. Li, L. Qiao and C. Yan, "Study on electric flux and corrosion rate of concrete," ACI Materials Journal, vol. 110, pp. 669-676, 2013.

[17] M. O. T. O. China, "Code for Design of Highway Reinforced Concrete and Prestressed Concrete Bridge and Culverts," in JTG D62-2004 Beijing: Ministry of Transport of the People Republic of China, 2004.

[18] E. Ryan, E. Burdette, R. Ankabrandt, R. Nidiffer, and B. Buchanan, "Comparison of two methods to assess the resistance of concrete to chloride ion penetration," Journal of Materials in Civil Engineering, vol. 26, pp. 698-704, 2014.

(C) Li et al.; Licensee Bentham Open.

This is an open access article licensed under the terms of the Creative Commons Attribution Non-Commercial License (http://creativecommons.org/licenses/ by-nc/3.0/) which permits unrestricted, non-commercial use, distribution and reproduction in any medium, provided the work is properly cited. 